\title{
PENGGUNAAN BAHAN BAKAR GAS TERHADAP SISTIM BAHAN BAKAR INJEKSI DAN MENGGUNAKAN SELENOID VALVE 12 VOLT SEBAGAI PENGAMAN UNTUK KONVERSI ENERGI ALTERNATIF PADA SEPEDA MOTOR YANG RAMAH LINGKUNGAN
}

\author{
Jusnita, Indra Hasan
}

Dosen Universitas Muhammadiyah Riau

Email: jusnita_ita@yahoo.co.id

\begin{abstract}
ABSTRAK
Bahan Bakar Gas (BBG) merupakan gas alam dengan komponen utamanya methana, jenis bahan bakar ini banyak ditemukan di Indonesia. Keuntungan dari penggunaan bahan bakar gas adalah lebih murah dari BBM, lebih ringan dari udara, usia mesin lebih lama, perawatan lebih murah dan tidak mencemari lingkungan. Salah satu penggunaan dari BBG adalah pada kenderaan roda dua. Metode yang digunakan dalam penelitian ini adalah dengan merancang sebuah alat yang digunakan untuk melakukan perubahan sehingga bisa memanfaatkan bahan bakar yang berbeda yang disebut dengan alat konversi (Converter). Pengujian dilakukan pada mesin sepeda motor injeksi berbahan bakar gas LPG $3 \mathrm{~kg}$ menggunakan alat uji dynotest dengan variasi putaran mesin. Hasil pengujian torsi maksimumnya adalah 8,55 Nm pada putaran mesin $5500 \mathrm{rpm}$ dan daya maksimumnya $7 \mathrm{Hp}$ diputaran mesin $6000 \mathrm{rpm}$. Untuk pengujian suhu pada putaran stasioner adalah $77^{\circ} \mathrm{c} \mathrm{dan}$ hasil uji sistim pembakaran pada busi dengan jarak tempuh $244 \mathrm{~km}$ warna busi abu-abu kemerahan hal menunjukan hasil pembakaran yang sempurna. Pada pengujiaan pengukuran emisi gas buang menggunakan alat Gas Analyzer Stargas mod 898 kadar $\mathrm{CO} 0,06 \%$, kadar $\mathrm{CO}_{2}$ 2,1\%, kadar $\mathrm{O}_{2}$ 20,53\% dan kadar $\mathrm{HC} 3234$ ppm. Berdasarkan hasil pengujian ini maka bahan bakar bakar gas LPG dapat digunakan untuk motor injeksi sebagai bahan bahan bakar alternative dan ramah lingkungan.
\end{abstract}

Kata kunci : Bahan bakar gas, konverter, injeksi, solenoid

\section{PENDAHULUAN}

Bahan bakar minyak (BBM) di Indonesia sekarang ini menjadi fenomena unik, karena perubahan pola perilaku manusia menyebabkan pola konsumsi masyarakat terhadap bahan bakar minyakpun mulai berubah. Fenomena ini berbanding terbalik dengan jumlah persediaan bahan bakar minyak dan batu bara di Indonesia. Dalam buku Outlook Energi Indonesia 2014 oleh Badan Pengkajian dan Penerapan Teknologi (BPPT) disebutkan bahwa pada tahun 2011, total cadangan minyak Indonesia sebesar 7,73 milyar barel yang terdiri atas sekitar 4,04 miliar barel cadangan terbukti (proven) dan 3,69 miliar barel cadangan potensial.

Bahan bakar minyak merupakan hasil olahan minyak bumi dan termasuk sumber daya alam yang tidak dapat diperbaharui. Prediksinya, sekitar tahun 2025 atau pada tahun 2030 Indonesia akan mengalami krisis energi, dengan kata lain persediaan minyak bumi akan habis. Sementara itu, bahan bakar pembangkit tenaga listrik masih bergantung pada solar dan batu bara, kendaraan bermotor membutuhkan bensin, pesawat terbang membutuhkan avtur, pembuatan infrastruktur jalan raya bergantung pada aspal, dan sebagainya. Minyak merupakan bahan bakar minyak yang sangat dibutuhkan oleh masyarakat Indonesia. Pemerintah memberikan subsidi kepada masyarakat dengan maksud untuk mengendalikan harga jual BBM sebagai satu kebutuhan dasar masyarakat didalam negeri, sehingga dapat terjangkau oleh daya beli masyarakat, terutama masyarakat berpenghasilan rendah. Hal ini disebabkan harga jual BBM dalam negeri sangat dipengaruhi oleh perkembangan berbagai faktor eksternal, antara lain harga minyak mentah dipasar dunia, dan nilai tukar rupiah terhadap dolar Amerika Serikat. Pada saat ini, BBM bersubsidi hanya diberikan pada beberapa jenis BBM tertentu, yaitu minyak tanah (kerosene), minyak solar (gas oil), premium kecuali untuk industri, dan (Liquefied Petroleum Gas) LPG tabung $3 \mathrm{~kg}$. Jenis BBM bersubsidi ini untuk keperluan rumah tangga, usaha kecil, usaha perikanan, transportasi dan pelayanan umum. 
Permasalahan umum yang dihadapi dunia pada dewasa ini adalah semakin menipisnya cadangan BBM disamping dampak negatif yang ditimbulkan dari penggunaan BBM tersebut. Bahan Bakar Gas (BBG) merupakan gas alam dengan komponen utamanya methana, jenis bahan bakar ini banyak ditemukan dihampir semua ladang minyak di Indonesia baik di daratan maupun di lepas pantai. BBG mulai diperkenalkan sebagai bahan bakar kendaraan bermotor di Indonesia pada tahun 1986. Pada tahun 1989 BBG mulai dipasarkan secara komersial dengan target pemasaran angkutan publik seperti mikrolet, bis kota dan taksi. Setelah berlangsung kurang lebih 13 tahun, pemasaran BBG di Indonesia tidak berkembang sebagaimana diharapkan. Saat ini BBG telah terbukti sebagai pilihan yang lebih baik dibidang transportasi. Data menunjukkan bahwa BBG yang mulai dicoba oleh pemerintah melalui pertamina pada tahun 1987 memiliki beberapa keuntungan diantaranya lebih murah dari BBM, lebih ringan dari udara, usia mesin lebih lama, perawatan lebih murah dan tidak mencemari lingkungan. Tapi masalahnya adalah perkembangan BBG di masyarakat sangatlah lambat. Hal ini disebabkan antara lain karena harga BBG tidak kompetitif dibanding BBM, harga konversi kit yang masih terlalu mahal, dan pemikiran masyarakat yang cenderung untuk selalu menggunakan BBM.

Tetapi kendala yang dijumpai pada perangkat konversi ini untuk kendaraan bermotor masih belum memberikan fungsi yang optimal, yaitu motor cenderung memiliki putaran tinggi pada kondisi idle, selain itu untuk melakukan akselerasi selalu akan terjadi keterlambatan dalam suplai bahan bakar ke ruang bakar sehingga menurunkan kinerja dari motor. Alat konversi bahwa kit konversi yang diimpor oleh beberapa penjual (vendor) di Indonesia masih memerlukan beberapa perbaikan. Beberapa penelitian yang telah diadakan untuk mencari penyebabnya, menyimpulkan bahwa masalah utama dari gangguan ini adalah ketidakstabilan dan respon transien yang kurang baik dari satu atau lebih mekanisme pegas massa yang terdiri dari restriksi katup, pegas, diafragma, saluran orifis, dan ruang dari regulator tekanan, Susanti, dkk. 2011. Untuk mengatasi permasalahan tersebut ditambahkan suatu perangkat sistim injeksi BBG yang dikendalikan secara elektronik.

Polusi dan pemanasan global akibat penggunaan BBM menjadi masalah besar serta kelangkaan BBM tanpa adanya alternatif bahan bakar lainnya menjadi persoalan di Indonesia. Fenomena ini mendorong peneliti untuk berusaha mencari bahan bakar alternatif yang diharapkan mampu mengatasi kedua permasalahan diatas secara serentak. Salah satu jenis alternatif yang dimungkinkan untuk menggantikan bahan bakar minyak terutama yang digunakan untuk kendaraan bermotor seperti pada sepeda motor yang menggunakan bahan bakar gas untuk sistim bahan bakar injeksi, diharapkan nantiknya dapat membantu pemerintah dan masyarakat dalam menghadapi krisis dari energy bahan bakar tersebut.

\section{METODOLOGI PENELITIAN}

Metode yang digunakan dalam penelitian ini adalah dengan cara pengujian stationer menggunakan alat uji dyanotes dengan variasi putaran mesin untuk mnentukan torsi dan daya maksimun serta melihat sistim pengapian dan emisi gas buang mengujikan alat uji Gas Analyzer Stargas mod 898.

\section{HASIL DAN PEMBAHASAN}

\subsection{Data hasil pengujian stasioner tanpa}

\section{beban}

Tujuan dari Pengujian adalah untuk mengetahui daya dan torsi maksimum yang terjadi pada sepeda motor injeksi berbahan bakar gas LPG $3 \mathrm{~kg}$ menggunakan alat uji dynotes dengan variasi putaran mesin tanpa beban seperti terlihat pada gambar grafik dibawah ini: 


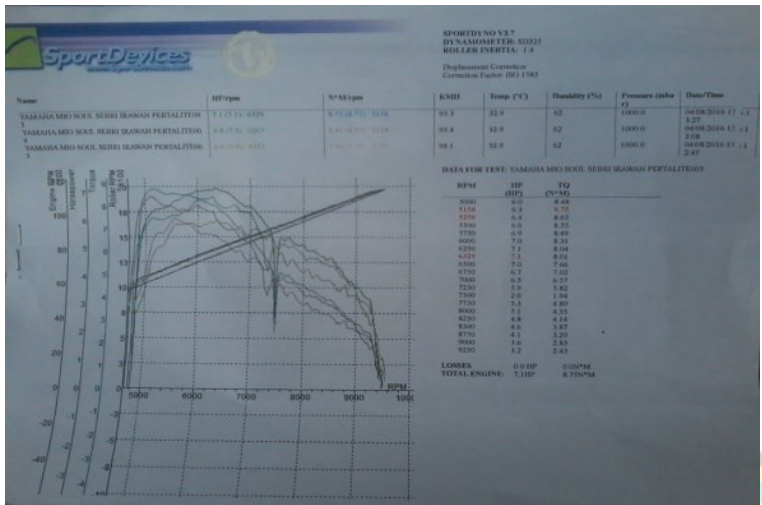

Gambar 3.1. data hasil pengujian torsi vs daya tanpa beban

Pada gambar 3.1. merupakan data hasil pengujian untuk mendapatkan nilai daya dan torsi maksimum. Untuk melihat hasil perbandingan torsi dan daya maksimum maka data hasil pengujian dapat ditabel seperti pada tabel 3.1.

Tabel 3.1. Data Hasil Pengujian Torsi vs daya tanpa beban

\begin{tabular}{|l|l|l|l|}
\hline No & $\begin{array}{l}\text { Putaran Mesin } \\
(\mathrm{rpm})\end{array}$ & Torsi & Daya \\
\hline 1 & 5000 & 8.48 & 6.0 \\
\hline 2 & 5500 & 8.55 & 6.6 \\
\hline 3 & 6000 & 8.31 & 7.0 \\
\hline 4 & 6500 & 7.66 & 7.0 \\
\hline 5 & 7000 & 6.57 & 6.5 \\
\hline 6 & 8000 & 4.55 & 5.1 \\
\hline
\end{tabular}

Dari tabel 3.1 dapat dilihat untuk torsi maksimum yang terjadi pada putaran mesin $5500 \mathrm{rpm}$ adalah $8.55 \mathrm{Nm}$ dan daya maksimumnya $6.6 \mathrm{Hp}$. Hal ini dapat dilihat pada gambar 3.2 hubungan antara torsi vs daya.

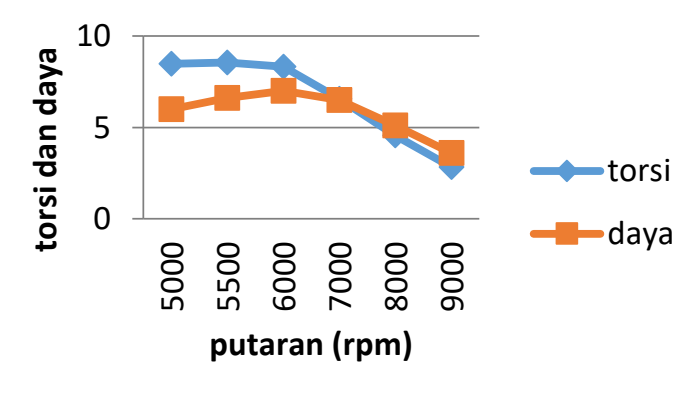

Gambar 3.2. Grafik hubungan antara Torsi vs daya tanpa Beban

\subsection{Data hasil pengujian stasioner dengan beban}

Gambar 3.2 menunjukan hasil pengujian Daya dan torsi maksimum yang terjadi dengan variasi putaran mesin dengan beban seperti terlihat pada gambar grafik dibawah ini :

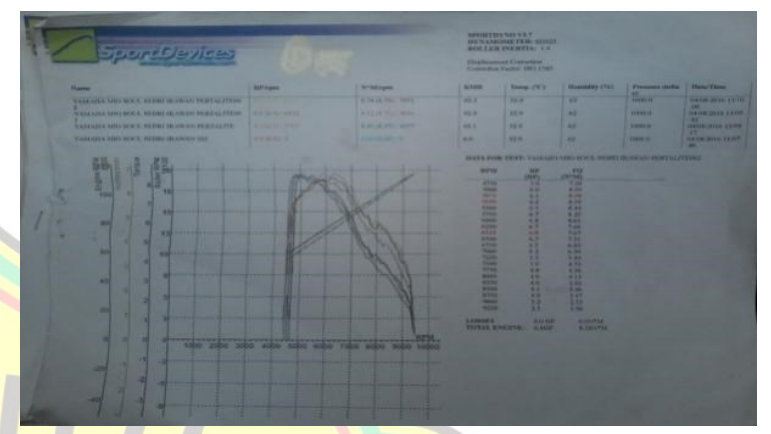

Gambar 3.3. data hasil pengujian torsi vs daya dengan beban

Pada gambar 3.3. adalah data hasil pengujian stasioner untuk mencari torsi dan daya maksimum dengan pembeban, maka data hasil pengujiannya dapat ditabelkan seperti pada tabel 3.2. dibawah ini :

Tabel 3.2. Data Hasil Pengujian Torsi vs daya

\begin{tabular}{|l|l|l|l|}
\hline No & Putran Mesin & Torsi & Daya \\
& $(\mathrm{Rpm})$ & $(\mathrm{Nm})$ & $(\mathrm{Hp})$ \\
\hline 1. & 5000 & 8.50 & 6.0 \\
\hline 2. & 5500 & 8.43 & 6.5 \\
\hline 3. & 6000 & 8.01 & 6.8 \\
\hline 4. & 6500 & 7.31 & 6.7 \\
\hline 6 & 7000 & 6.30 & 6.2 \\
\hline 7 & 7500 & 4.72 & 5.0 \\
\hline 8 & 8000 & 4.13 & 4.6 \\
\hline
\end{tabular}

Hasil pengujian pada tabel 3.2 menunjukan torsi maksimum yang terjadi pada putaran mesin $5000 \mathrm{rpm}$ dan daya maksimum $6,8 \mathrm{Hp}$ terjadi pada putaran mesin $6000 \mathrm{rpm}$. 


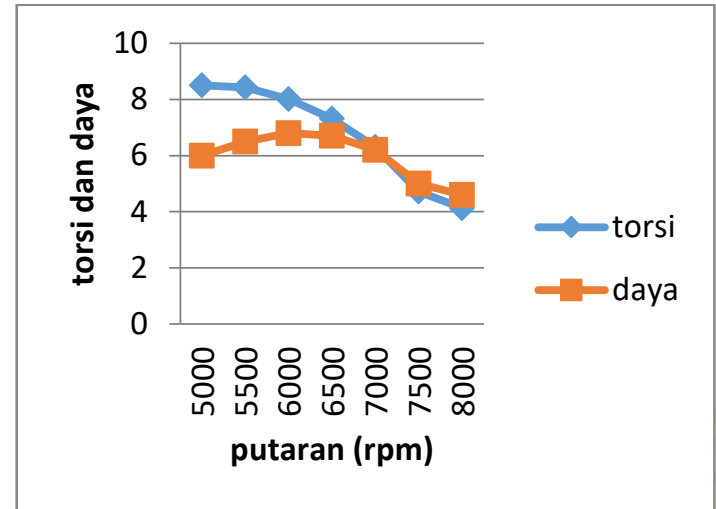

Gambar 3.4. grafik hubungan putaran mesin vs torsi dan daya

\subsection{Pengujian suhu}

Tujuan pengujian ini adalah untuk mengetahui suhu yang terjadi diwaktu pengujian stasioner dalam waktu 15 menit.

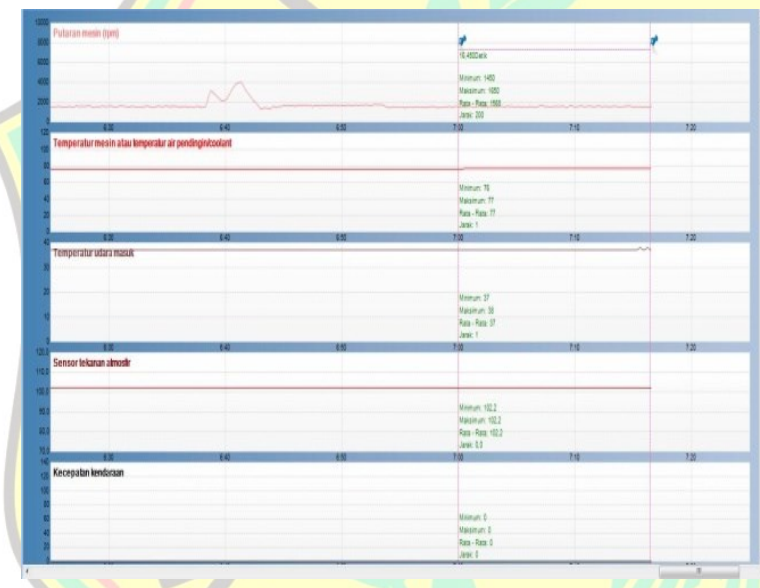

Gambar 3.5. Grafik hasil pengujian

$$
\text { temperatur }
$$

Dari hasil pengujian maka didapat suhu mesin untuk $77^{\circ} \mathrm{c}$. Bila dibandingkan dengan sepeda motor bahan bakar premium suhu mesinnya mencapai $69^{\circ} \mathrm{c}$. Hal ini disebabkan karena saluran masuk udara tidak full terbuka supaya gas bisa langsung masuk keruang bakar.

\subsection{Pengujian Sistim Pengapian}

Pengujian hasil pembakaran pada bahan bakar gas LPG ini dilakukan dengan cara melihat warna pembakaran pada busi setelah menempuh jarak tempuh $244 \mathrm{~km}$ pada sepeda motor injeksi. Maka hasil pembakaran yang terjadi pada busi warnanya seperti warna abuabu kemerahan, seperti pada gambar dibawah ini:

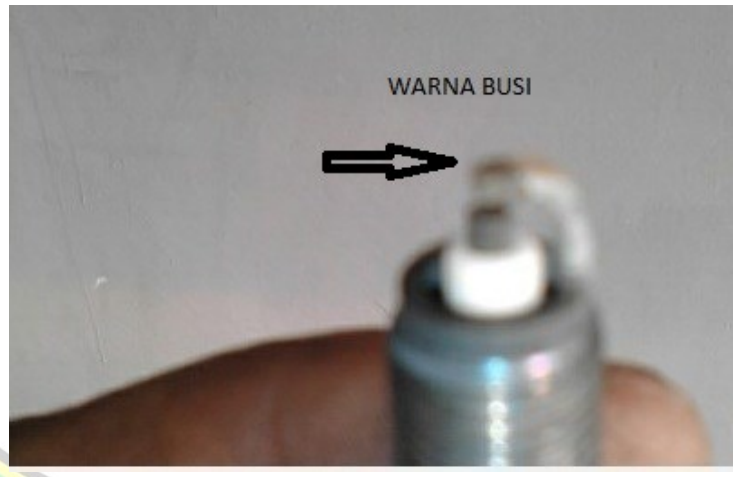

Gambar 3.6 Warna busi setelah pemakaian

Pada gambar 3.6. warna busi setelah melakukan pengujian dengan menempuh jarak tempuh $244 \mathrm{~km}$ untuk kendaran bahan bakar gas LPG $3 \mathrm{~kg}$, maka hasil pembakaran busi berwarna abu-abu kemerahan hal ini sudah sesuai dengan standar warna busi seperti terlihat pada no. 9 dibawah ini.

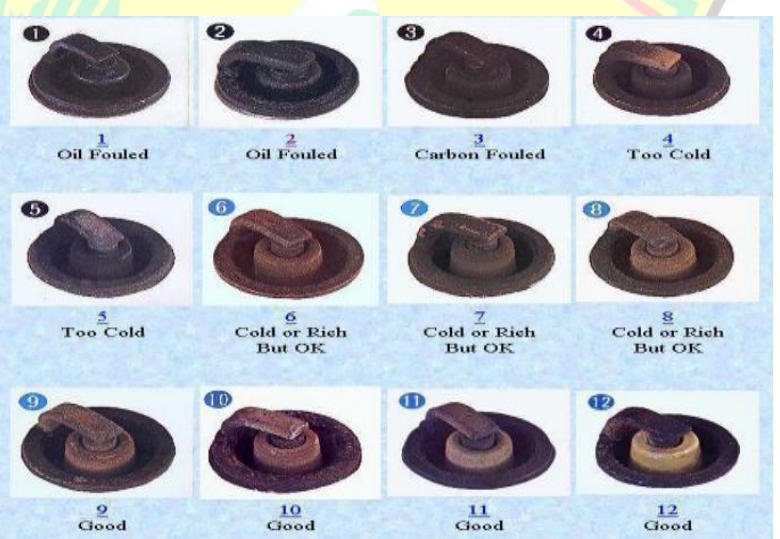

Gambar 3.7 Standar warna busi

Bila dibandingkan dengan hasil pembakaran pada busi kendaraan roda dua yang berbahan bakar premium dengan jarak tempuh, kecepatan dan kondisi jalan yang sama dengan hasil pembakaran busi berbahan bakar gas LPG $3 \mathrm{~kg}$, maka hasil pembakaran busi bahan bakar gas lebih baik dibandingkan bahan bakar premium. Hal ini dapat di lihat pada gambar di bawah ini: 


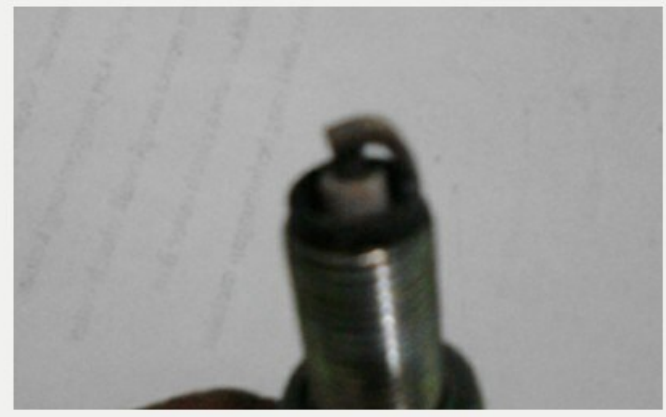

26.08.2015

Gambar 3.8 warna hasil pembakaran busi premium

\subsection{Pengujian Emisi Gas Buang}

Untuk mengetahui emisi gas buang yang terjadi pada sepeda motor injeksi berbahan bakar gas LPG dengan kendaran roda dua berbahan bakar premium, maka hasil dari pengujian emisi gas buang pada sepeda motor gas LPG nilai CO lebih rendah, seperti terlihat pada tabel 3.3 .

Tabel 3.3. Hasil pengujian emisi

\begin{tabular}{|c|c|c|c|c|c|}
\hline No & $\begin{array}{c}\text { Bahan } \\
\text { Bakar }\end{array}$ & $\mathrm{CO}$ & $\mathrm{CO}_{2}$ & $\mathrm{O}_{2}$ & $\mathrm{HC}$ \\
\hline 1. & $\begin{array}{c}\text { Premium } \\
(\mathrm{FI})\end{array}$ & $\begin{array}{c}0,25 \\
\%\end{array}$ & $\begin{array}{c}4,9 \\
\%\end{array}$ & $\begin{array}{c}18,67 \\
\%\end{array}$ & $\begin{array}{c}183 \\
\mathrm{ppm}\end{array}$ \\
\hline 2. & LPG & $\begin{array}{c}0.06 \\
\%\end{array}$ & $\begin{array}{c}2,1 \\
\%\end{array}$ & $\begin{array}{c}20,53 \\
\%\end{array}$ & $\begin{array}{c}3234 \\
\mathrm{ppm}\end{array}$ \\
\hline
\end{tabular}

Dari tabel diatas maka sesuai dengan standar baku emisi gas buang untuk kendaraan roda dua tahun 2013-2015 dari kementerian lingkungan hidup.

\section{KESIMPULAN DAN SARAN}

Dari hasil penelitian untuk sepeda motor sistim injeksi yang menggunakan bahan bakar gas LPG $3 \mathrm{~kg}$ maka torsi maksimum yang terjadi adalah 8,55 $\mathrm{Nm}$ pada putaran mesin 5500 Rpm dan daya maksimum 7, 0 Hp pada putaran mesin 6000 Rpm tanpa beban. Sedang untuk yang berbeban torsi maksimumnya $8,50 \mathrm{Nm}$ pada putaran $5000 \mathrm{Rpm}$ dan daya $6,8 \mathrm{Hp}$ pada putaran mesin $6000 \mathrm{Rpm}$. Pada pengujiaan pengukuran emisi gas buang menggunakan alat Gas Analyzer Stargas mod 898 kadar CO 0,06
$\%$, kadar $\mathrm{CO}_{2} 2,1 \%$, kadar $\mathrm{O}_{2} 20,53 \%$ dan kadar HC 3234 ppm. Sehingga berdasarkan hasil pengujian ini bahan bakar bakar gas LPG dapat digunakan untuk motor injeksi sebagai bahan bahan bakar alternative dan ramah lingkungan.

\section{DAFTAR PUSTAKA}

Suparman, 2014, "Pemanfaatan Gas Lpg $3 \mathrm{Kg}$ Sebagai Bahan Bakar Alternatif Pada 
Sepeda Motor Pengganti Bahan Bakar Minyak (BBM), Kreatifitas Dan Inovasi Guru

Atok Setiayawan, 2012, Teknologi Konversi Energi Bensin Ke Bahan Bakar Gas.Jurnal Teknik Mesin ITB

Achmad Fauzan HS,2012,"Disain Converter Kits Modifikasi Sistem Bahan Bakar Motor Bensin Menjadi Berbahan Bakar Gas,"Jurnal Gamma

Susanti, dkk. 2011. "Kebijakan Nasional Program Konversi dari BBM ke BBG untuk

Kendaraan". LIPI PressJakarta

BPH Migas,2007, "Perbandingan udara dan bahan bakar dalam bentuk volume pada pemakaian bahan bakar gas",blogspot.com

Hadi Purnomo,2006, "Badan Pengkajian dan Penerpan Teknologi", Jurnal Teknik Mesin ITB

Iswandi, 2003. "Kajian SistemPengisian Bahan Bakar Gas Untuk Kendaraan Bermotor" Pustaka Iptek, Jurnal Saint dan Teknologi BPPT.

Tulus BS. 2002, "Tinjauan Pengembanga Bahan Bakar Gas Sebagai Bahan Bakar

Alternatif", Jurnal Teknik Mesin Universitas Sumatera Utara

Fred Hammond dkk, 1996, "Bi-Fuelsound Environmental Solution To Vehicle Exhaust”, V6-04, Volvo 850. 